\title{
Backpacking with a Prayer: Tradition and Modernity
}

\author{
Nitza Davidovitch \\ Correspondence: Nitza Davidovitch, Ariel University of Samaria, Ariel, Israel. \\ Received: May 28, 2016 Accepted: June 12, $2016 \quad$ Online Published: June 17, 2016 \\ doi:10.11114/jets.v4i9.1679 \\ URL: http://dx.doi.org/10.11114/jets.v4i9.1679
}

\begin{abstract}
This study focuses on the phenomenon of Israeli backpacking as a function of traditional, observant, and secular population segments. We explored whether and to what degree backpacking features are related to the affinity of backpackers with the Jewish tradition and faith. Our study was based on a sample of 120 Israeli backpackers who had returned to Israel in the past five years. An analysis of the survey indicates a clear association between the length of the backpacking trip and the affinity of backpackers with the Jewish tradition and faith. We also found that backpackers on lengthy trips tended to engage in events or rituals related to religion to a greater degree compared to backpackers on shorter trips. An interesting finding was that backpackers on lengthy trips felt closer to Jewish tradition and observed religious precepts more than backpackers on shorter trips. These findings imply that the longer Israeli backpackers remain abroad, the stronger their affinity with Jewish tradition. One question that arises is whether the distance from Israel fosters a sense of nostalgia for Jewish culture, or whether backpackers on longer trips undergo a more spiritual experience during their time abroad.
\end{abstract}

Keywords: backpacking, leisure, tradition, modernity

\section{Introduction}

In recent years we have been witnessing an increasing incidence of young Israelis who embark on lengthy backpacking trips. The trips have become a post-army norm and some see the "big trip" as a direct continuation of their military service. In contrast, others perceive the trip as an act of rebellion against the regular course of life ("moratorium") in which another stage is added to the Israeli trajectory (Bar, 2000; Boni-Noah, 2012), by young people who wish to postpone their obligations to the expected social routines.

In most cases, the backpackers leave the country immediately after completing their military service or after a short period of employment aimed at financing the trip. The nature of the trip is outlined by the wish to take a break from the formal, strict, danger laden circumstances of the army. The backpackers wish to rest, relax, and create an experiential barrier between their military service and their future civilian life (Noy, 2003).

Backpacking has become a type of social institution that offers a rite of admission and passage from youth to adulthood, implemented by people of a similar age and background who share the same beliefs and opinions (Boni-Noah, 2012). Israeli backpackers meet their friends in hostels, shops, and Israeli restaurants (Noy, 2003).

The association between the backpackers and Jewish tradition has gradually developed in recent years. The number of Chabad emissaries abroad has grown, as well as the number of Chabad Houses. This organization helps preserve Jewish tradition among Israeli backpackers during their travels.

The current study focuses on Israeli backpacking as a function of the various segments of the population: traditional, religious, and secular. The study examined whether and to what degree the features of the trip are associated with the affiliation of backpackers with the Jewish tradition and faith. The researchers chose to focus on backpackers who define themselves as secular, with the purpose of exploring whether and to what degree they participate in religious-type events during the trip, and if so - what motivates them to do so?

\section{Israeli Backpacking}

The late 1960s and early 1970s were the height of international backpacking among the younger generation. In Israel at that time, conditions were not ripe for the social legitimization of taking a break from life and travelling for a lengthy period with no defined purpose ("take your time"). Young travellers are normally an indication of affluent societies (Shafran, 2006), who can allow their younger members to set aside existential and survival problems (battles for the society's existence) and challenges (such as immigration absorption). In those years, Israeli society was occupied with 
the existential needs of the collective, with the "we", rather than with the yearnings of the individual, the "I" (Almog, 2004). The challenges encountered by the young were part of the challenges of contemporary Israeli society. Personal challenges such as individual and intellectual progress (studying, making a profit) did not occupy young people, raised as they were on principles of collectivism (contribution to society, serving the country); the former were considered a type of disloyalty and a way of evading the necessary endeavours ("The Ballad of Hedva and Shmulik"). Notably, the young generation was also not rebellious - on the contrary, it was literally a generation of "do-gooders". People did not try to stand out by wearing unique clothes or displaying different behavior patterns than the norm. The concept of the "gang" (hevre or hevraya) was in full force, no one wished to be different. The goal was to fit in with the group (Shafran, 1999). Only in the decade after the Six Day War (in 1967) did Israel begin to prosper:

1.In those years the first generation born to Israeli-born parents or to those who had arrived in the country at a young age, reached maturity. The generation that had grown up with the country, who reached maturity in the 1960s, had been born to immigrants. The grandchildren of these immigrants were raised in families with a relatively strong socioeconomic status. Their parents had been born or raised in Israel, they had been through the educational and military systems and knew them well, and they did not require the help of their parents, unlike the previous generation who had to help out their immigrant parents. The Israeli born parents were sufficiently strong and well established that they could not only help their children travel abroad but also come and bail them out if they got into trouble (Shafran, 2006).

2. An important external influence was that of foreign volunteers who came to work on the kibbutzim (plural of "kibbutz"). When the first volunteers arrived in the country following the Six Day War victory, Israeli society was not yet ready, in many respects, to send its younger generation to tour the world, although they were the same age as the volunteers. But the influence of the volunteers gradually trickled through. Naturally, those affected were mainly the kibbutz youth, some of whom saw the volunteers as role models.

3.In addition to the economic and social conditions, there were also political factors that did not allow the backpacking phenomenon to develop in the same decade when western youngsters set out to conquer the world. The Six Day War was the constitutive experience of members of the first generation raised in an independent Israel. The Yom Kippur War was the initial stimulus for backpacking trips, as stated by some of the first backpackers (Shafran, 2006), in the sense of "taking in some fresh air" as a respite from the unease generated by the war.

4.In the 1980s, the backpacking phenomenon became more established. The Lebanon War served to enhance this trend. The mid-1980s in Israel, with Lebanon and the Intifada, were reminiscent of the 1970s in the US: a ruined dream, in the words of author and culture critic Gadi Taub (2003), speaking of his generation who reached maturity in those years and transformed backpacking into a mass phenomenon.

In summary, Israel's war of existence, both on the military sphere and on the daily existential sphere, may be said to have left its mark on Israel's backpacking scene, perhaps more so than anywhere else in the world. Backpacking is now an inseparable part of Israel's cultural-social-natural climate, as a young country.

\subsection{Backpackers - Destination?}

1. Israeli backpackers headed at first for South America in very limited numbers. In the first years they consisted of a core group of kibbutz members and former combat soldiers, whom Yaakov HaElyon, an Israeli journalist, called "Knights of the Muchileros Order" (1980). In 1980, some 400 backpackers were estimated to have visited South America. Backpacking was already a given. But then, it was hard to guess that backpacking, a term that wasn't even in use at the time, would grow to become a mass phenomenon. It was treated as a passing fad (Finkel, 2003; Shafran, 2006).

2.In time, Israeli backpackers began to discover other continents, particularly the Far East. The trips gradually spread to include many thousands of young men and women. In contrast to the large wave of backpackers in the late 1960s, mainly Americans, that disappeared in about a decade, Israeli backpacking has persisted for decades and is still going strong (Halfon, 1991; Samocha, 2003; Shafran, 2006).

"The Zionist trip" first emerged during the First Aliya (first wave of immigration to Palestine), when teachers at schools in the moshavot (agricultural towns) would take their pupils on short hikes. In the early $20^{\text {th }}$ century, scouting activities first reached the country (The Scouts Association in the Land of Israel was founded in 1919) and helped recognize hiking as a physical challenge. In the beginning of the Third Aliya, members of Hashomer Hatza'ir brought with them the "wandervogel" culture of the German youth movement, centering on nature outings. Hikes in the Land of Israel became a familiar pastime in the 1940s as part of the Palmach. Some see backpacking as a direct continuation of this type of outings. Chaim Noy (2003), who investigated backpacker hikes, found a direct link between them and Israel's hiking tradition. In dozens of interviews conducted with backpackers, he found Israel's landscapes reflected in their 
stories. Not the daily landscapes the hikers had seen when growing up but those familiar to them from hikes around the country, in the youth movement and in their military service, and particularly the national sites appropriated in Israeli culture as symbols of the homeland and constituting sites of pilgrimage, such as Massada and the Judean Desert. In his opinion, the backpacking trips are culturally and socially connected to Israeli hikes and are a continuous Zionist practice. It is no coincidence, he says, that backpacking of all activities has become a recognized collective rite of passage among Israeli youngsters (Shafran, 2006).

\subsection{Marks typical of Backpackers}

In time, many changes have occurred in the external signs of the trip: khaki pants were replaced by jeans, the knitted hat and the bucket hat by the American baseball cap, the cumbersome shoes of old, whose leather soles often had to be replaced during the trip, were replaced by brand name hiking shoes, and the old canvas backpacks by hi-tech backpacks holding the most advanced camping equipment. Even the word trip, or hike, was replaced in the recent generation by another term: trek. Dalit Simchai, who explored the topic of Israeli backpacking in the Far East, perceives the word "trek" as part of a backpacker subculture, joining words such as guest house and porter. Noam Cohen, who travelled in South America in 1989 and was killed several years later in Ramallah by Hamas, explained the trek in a letter to his parents: a several-day hike/trip in the mountains rather than in urban areas is often called a "trek". This is, in fact, a hike in which food for the next few days and personal equipment, including a sleeping bag, tent, coat, etc., are carried on one's back. In a letter to a friend, he wrote that a trek is simply a several-day hike, carrying all the food, hiking, and sleep equipment (Shafran, 2006).

\subsection{Backpacking as an Experience}

The heart of the backpacking experience is not the entertainment, the fun. The hiking is difficult and strenuous and is certainly not undertaken for pleasurable purposes. The trek is a work space that must be conquered, crossed, and studied closely and thoroughly. The trek is, in fact, an embodiment of the constitutive experience of Israeli youth: military service, in which a small close-knit group repeatedly withstands tests of physical endurance and many other dangers. For the backpackers, considered the elite of the Israeli social hierarchy, the trek is a refined manifestation of the backpacking experience. Notably, the Palmach, the youth movements, and select units of the IDF were exclusive as well, but these were top elite that inspired others with their values (Ghinsberg, 1985; Lee, 2003; Paltin, 2003; Shafran, 2006).

Most of the backpackers experience the familiar sense of Israeli togetherness. This may be manifested in many forms, but its supreme realization is still through a hike by a small cohesive group. From this respect, although the backpacking trek takes place far from Israel's borders, the dynamics formed within it are very similar to those of the Israeli hike. The Israeli hike is a demonstration and test of collective willpower and persistence and a type of collective self-restraint that constitutes a declaration of loyalty to the Israeli system and, indirectly, also to the nation and to the country (Shafran, 2006).

The backpacking phenomenon, which in the last decade has become a central element of Israeli society, is complex and manifold. It has received many explanations, often conflicting. Some see the "big trip" as a direct continuation of their military service. Others see it as a distinct antithesis of the Israeli collective military experience. Some see the backpacking trip as a way of rebelling against the set course of school-army-university-marriage-work-children; others as one of the established stages of the Israeli course of life (Shafran, 2006).

The post-army backpacking trip, or as it is sometimes called the "big trip", has become a significant social phenomenon within Israeli society. Anthropologists state that for the youngsters the trip is a type of "rite of passage" from adolescence to adulthood. In their opinion, the young backpackers are in a state of moratorium (postponement of social obligations) during the trip. Some see the trip as a means of escape and segregation from society, which is perceived as demanding and a source of pressure. Some state that the trip is an opportunity to explore one's values (Boni-Noah, 2012).

The backpackers have completed a lengthy military service and they must reach important decisions concerning their future. The backpacking trend has become part of the "normal" Israeli course. These backpackers are mainly young middle-class secular Jews (Uriely, Yonay, \& Simchai, 2002).

According to Foreign Ministry estimates, some fifty thousand Israelis go on the trip every year, mainly to the Far East and South America (Boni-Noah, 2012). There is indeed no information on the precise number of people who go on such a trip, but one study indicated that about $10 \%$ of soldiers released from the army subsequently spend more than five months in developing countries. Nonetheless, there are also signs that the trend is larger than reflected by this datum. As a result of the backpacking phenomenon, special shops and restaurants have opened in many countries to serve backpackers, and Israeli insurance companies offer special plans for these travelers (Uriely et al., 2002).

Israelis travel to the Far East mostly in transition phases of their life. The most common stage is after completing their 
military service, a point in time that symbolizes the conclusion of formal obligations and the beginning of civilian life. The next stage is in their late twenties, right before they settle down and enter adulthood, the next is in mid-life - in their forties and fifties, and the final stage is retirement (Maoz, 2003; Dayan, 2004).

The post-army trip is the more conventional backpacker trip. This is often called the "big trip", and it has become part of the life course of Israeli adolescents. The backpackers feel rebellious, and they are often seen as such, but in fact their trip is completely conformist (Sagiv, 2001; Maoz, 2003).

The travel experience is complemented by spontaneous sing-along evenings that go on until late at night at the hostels. Someone playing a guitar (which has replaced the accordion, which replaced the harmonica) leads the group from song to song, even if most of the songs are no longer old-time Israeli favourites.

These sing-along evenings are the best part of the trip. A type of prolonged journey among friends, perhaps the last journey before entering the adult world. This is an internal Israeli experience that cannot be shared with anyone else. It can't be experienced together with other travelers, whether Dutch, Australian, or British. The Israelis find themselves gathering in groups and spending time mainly with each other. They have no language restrictions, and their thoughts follow a similar course (Shafran, 2006).

The incredible development of the internet in the early $21^{\text {st }}$ century helps maintain contact between members of the groups in a way that was not possible in the $20^{\text {th }}$ century. The backpackers constantly update each other and report to all those they met along the way where they are and their plans for the future. They no longer travel only with those who are physically with them, rather also with all the friends they met (Shafran, 2006).

Travelling at this age gives the backpackers mainly the independence and maturity that they lacked in the army, where they obeyed strict rules and laws. The trip is the first separation from their parents. Israeli soldiers are indeed physically far from their families but they are still economically and mentally dependent on them, and only during the trip do they manage to leave their parents behind in all respects for the first time: do their own laundry, cook their own food, reach their own decisions (Maoz, 2003).

Israeli backpackers are a group characterized by cohesiveness and by particularly strong interpersonal relationships. They tend to remain within the group and not mix with others (more so than European tourists) and their trip is directly linked to their military service. On one hand the trip attempts to be the opposite of the military service by including activities that deviate from the norm (drugs, sex, breaching norms), but on the other it is a direct continuation of the army service (the cohesiveness, manner of conduct, slang). The trip is also a continuation and a complement to the rite of passage to adulthood that the backpackers did not have the chance to complete as soldiers as they were still significantly connected to their parents (Maoz, 2003).

The Israeli government's attitude to backpacking reinforces the sense of backpacking as continuing trips within Israel. The attitude of the establishment is manifested first and foremost in responses to disasters and trouble. The support and backing provided by the State of Israel in such cases reinforce the phenomenon and award it "moral" legitimization. Israel promises support, help when in need, and thus appears to encourage the risks taken by disregarding them. Ambassadors and consuls take personal care of backpackers' problems, in a way that would never occur to backpackers from other countries. It is as though the military course continues abroad, overseas, and every backpacker is a soldier who must complete his assignments and prove his bravery everywhere and at all times, and indeed, the attitude to the extraction of backpackers, whether dead or alive, is reminiscent of Israel's attitude to the ransoming of prisoners of war, abducted soldiers, and even dead soldiers in enemy territory (Shafran, 2006).

\subsection{Backpacking as Part of the Concept of Leisure in Traditional Societies}

"Leisure - time not dedicated to fulfilling obligations, in which activities are voluntary, enabling one to express one's needs and inclinations." Namely, leisure is time that is not devoted to work or to any other personal obligation. Leisure is characterized by voluntary actions and contents. Leisure is defined as a psychological level of pleasure. Leisure is a major aspect of human life and people differ in the quantity of their leisure, hours of leisure, and how they spend their leisure time (Katz \& Yanovitzky, 1999).

Similar to holidays, a vacation is a break in one's daily routine and a special festive time. But unlike holidays, it is a private and permissive time with regard to collective values, customs, and ceremonies. Expectations of vacations outside the home are to forget one's obligations, to spend time with family and friends, and to enjoy special experiences (Hass, 2000).

A break is any action that constitutes a departure from one's daily routine. For example holidays, ceremonies, as well as national, religious, and personal breaks:

National breaks - For example Holocaust Memorial Day, Memorial Day for Fallen Soldiers. 
Religious breaks - For example, religious holidays - the Festival of Tabernacles, Passover.

Personal breaks - In this instance a vacation can be a personal break.

Some claim (Hass, 2000) that taking a break from routine is an opportunity to connect with various dimensions associated with people's society.

Huizinga (1966) refers to all daily operations as part of culture. In his opinion, these can all be examined by the same criteria. A break is not only an interval between times or between two operations, rather a meaningful period, which helps one connect to dimensions that are not always rational. Several criteria are used to define human games, mainly for social ceremonies. This forms a parallel between breaks and games. He presents several criteria:

1.Separation - Both when playing games and when on a break there is a dimension of separation from routine in favor of connecting with another act that has a separate meaning. For example: the backpacking trip is a break in routine in favor of an operation that has its own meaning.

2. Time - Huizinga (1966) claims that a break occurs in its own time. Games have a beginning, middle, and endpoint and even an internal rhythm. The backpacking trip too has a beginning, middle, and endpoint.

3. Location - Every game or break takes place in some location. This can be a physical location or a virtual location.

4. Rules - Every game or break involves a different set of rules, which are binding and must be taken seriously. Backpacking trips as well have binding rules.

5. Dressing up - On a break participants sometimes dress in attire unlike their regular clothing, distancing them from their routine (Huizinga, 1966).

The research of leisure, which examines the significance of Jewish holidays for Israelis (religious break), indicates that:

1. National holidays - Independence Day and Memorial Day for Fallen Soldiers, for example, receive more weight than universal holidays (May Day, New Year's) and are a break from routine around which Israeli society gathers. This gathering is manifested in certain ceremonies; consumption of media ceremonies is mainly through television and radio.

2. Day of Atonement - This day has religious and secular significance for extensive parts of the population. The secular meaning derives from the Yom Kippur War and this too is manifested in certain media consumption (in holiday newspapers).

3.Passover and Rosh Hashana (the Jewish New Year's) are considered family holidays (particularly Passover).

4. National unity is facilitated, to a large degree, precisely by the multiple meanings of the holidays. This means that there is a special attitude to the holidays, although it is not uniform and thus it is possible to refer to breaks as creating social integration (Hass, 2000).

Turner (1977) spoke about symbolic breaks that ultimately represent the individual's unity with the collective. This is a process of uniting the collective in rites of passage.

Liminality - A process the participants undergo when taking part in the rite of passage. This means that in the rite of passage there is an intermediate state - a passage from one status to another, with an emphasis on the passage. This liminal state is the state of the ceremony per se. A ceremony is a process that transfers the hegemony. In the liminal state, participants are separated from their daily existence and from that which preceded the ceremony, but they have not yet connected to the post-ceremony reality. This state is characterized by participants' awareness of being separated from the daily routine and particularly aware of the social values that arise during the ceremony. In the rite of passage, values are conspicuous and participants feel free to refer to them at ease, namely there is some sort of release from routine in favor of reconstructing the hegemonic meaning. The existing social order appears to be challenged, but ultimately it returns to its natural routine state. This is a stop for refreshment and continuity.

Turner and other culture and media researchers claim that it is possible to expand the definition of the liminal state; thus even consumption of culture, such as attending a play, is a type of liminal state. For some researchers, even watching television is a partially liminal state.

Turner further says that by consuming culture one connects to all kinds of truths about life, about reality. Turner shows us how taking a break unites society by challenging the central values (for example, in a rite of passage major values are reaffirmed) that arise during the ceremony, and reaccepting them in their hegemonic meaning (Turner, 1977).

\subsection{Religion, Culture, and Tradition}

Culture can mean a type of religion, or it can mean a country of origin. Culture is inclusive, so it is better to use the term "group", meaning a multicultural society, as Israeli society is composed of many groups. The group sets a boundary 
between itself and other groups and these boundaries are evident when the group demands something of the collective or of the political establishment. For example, the group's demand to remove boundaries in order to achieve equality, or to the contrary, a demand to retain the boundaries in order to honor the right to self-determination (Calderon, 2000).

The national culture, intended to shape the world of the new Jew, who was also expected to create this culture single-handedly, was characterized not only by a complex attitude to tradition and to religiosity in general. Moreover, from many respects the endeavor of creating a new Jewish culture was part of long-term trends consisting of a conflict over sanctity and its redesign in the spirit of modern nationalism, a conflict that took place on a much wider field than the Jewish and Zionist field, and one of whose major global battlefields was in the Land of Israel. From this perspective secularization per se, and the modernity with which it has become integrated, is perceived not only in contrast to the traditional, rather also as a way of preserving a relationship with the very tradition that it presumes to inherit. Thus, the process of shaping the new Jew stemmed from a dialectic relationship between innovation and invention on the one hand and between a type of adoption and continuation on the other, with a new emphasis on elements, symbols, rituals, customs, and traditional memories (Saposnik, 2009).

The arrival of the Jews in the modern era, or as it is called the "multi-modern era", challenged their collective identity and undermined an identity that had been obvious and clear for dozens of generations. Religion is at the core of the traditional culture and, therefore, it is also an issue dealt with by modern civilization. Traditional historic Judaism defines Jewish identity by the three principles of "Torah of Israel - God of Israel", "People of Israel", and "Land of Israel". Nonetheless, as reflected in its changing approaches to the concept of conversion, it shifted from an emphasis on the territorial domain, the "Land of Israel" and the people in the Land of Israel ("People of Israel") to an increasing emphasis on the dimension of religious faith ("Torah of Israel and God of Israel"). This Judaism clarified the conversion patterns and linked them to becoming part of the "People of Israel", and the territorial element was marginalized as a topic dependent on realization of the entire religious vision. Hence, it is clear that traditional Judaism is a "non-Israeli" Judaism. It indeed determines that the "Land of Israel" is a holy land for Jews and any other place is perceived as "exile" or "diaspora", but it also asserts that the "exile" is "temporary" (Ben-Rafael \& Ben-Chaim, 2006).

"We are Jews in real life, in our heart and emotions, with no intellectual definitions, with no absolute truths and with no written commitments. Everything that is precious to us today, everything that has value for us, everything that derives from our free essence - without coercion, whatever it may be - that is our Judaism" (Yosef Haim Brenner).

After a period of diminishing religious activity within Israeli society, in recent years a renewed flourishing of this activity is evident. Nevertheless, the new religious activity in the secular domain is characterized by completely different components than the traditional activity. It is less official, it has almost no organized hierarchies, it espouses a creative approach to tradition while also clearly seeing itself as part of a multi-generational chain. Tradition mixes with new trends not from a desire to protest but precisely from a desire to expand the boundaries, to stop defining, and to create the possibility that is so rare in Israeli society of choosing a hybrid identity inspired by different sources with no unambiguous identification (Azulay \& Tabory, 2008).

In all issues related to religion and backpacking, Shafran claims that she had an opportunity to observe the nature of Israeli backpacking during her own trip, and she relates receiving the impression that most of the backpackers have little interest in places connected to local history and in places connected to Jewish history. The backpackers headed, in fact, only for those places where the Jewish community offered free or almost free services, a place to sleep, a Passover Seder, or some "experience" (Shafran, 2006).

Then again, Israeli backpackers take with them on the trip a significant part of Israeli culture and of the Jewish religion. In the enclaves created by the Israelis the Hebrew language is heard everywhere, there are many Hebrew signs: in shop windows, on restaurants, and even on walls in the street and in hostels. Menus in the restaurants are in Hebrew, and the food is completely Israeli. Israeli backpackers stay together and sit in large groups, listen to Israeli music, speak Hebrew, read Hebrew books, surf the web in Hebrew and correspond on e-mail in Hebrew. Chabad Houses spread throughout the Far East serve as a place where Israelis can gather, allowing them to maintain a religious life, as well as Jewish customs and traditions. Israelis come to Chabad Houses on Friday nights and festival eves, study courses in Kabbalah and hear lessons given by the Chabad emissary (Maoz, 2006).

As stated, in this study we shall deal with the association between the phenomenon of Israeli backpacking as a function of the population segments - traditional, religious, and secular. We examine whether and to what degree there is an association between the features of the backpacking trip and backpackers' affiliation with the Jewish tradition and religion. Furthermore, whether and to what degree does the physical distance from Israel create a sense of nostalgia for the Jewish culture or is there a deeper spiritual experience that occurs during the trip. 


\subsection{Study Methods}

\subsubsection{Research Population}

According to estimates provided by the Israeli Foreign Ministry, some fifty thousand Israelis go on a post-army trip every year. This is called the "big trip" and it has become part of the trajectory of Israeli adolescents. We administered a questionnaire to backpackers from several age groups, who set out on trips of various durations. We sampled the affiliation of younger and older backpackers with religion as related to the length of their trip: short trips of up to 4 months, or long trips of more than four months (Boni-Noah, 2012). The study was conducted in 2015 and it consisted of 120 backpackers.

\subsubsection{Research Tools}

One hundred and twenty backpackers who defined themselves as secular completed a questionnaire with four parts:

1. Affiliation with the Jewish tradition.

2. Feeling close to the Jewish faith during the trip.

3. Feeling close to Jewish tradition.

4. Observation of religious precepts.

\subsubsection{Research Procedure}

The researchers began to collect material and data that served as a background for the study in November. After the questionnaire was composed and distributed the findings were processed and analyzed.

\subsubsection{Research Hypotheses}

The research hypotheses were that the longer the backpacking trip:

1. The higher the affiliation of backpackers with the Jewish tradition, compared to backpackers on a short trip.

2. Backpackers were more inclined to talk about topics involving the faith, compared to backpackers on a short trip.

3. Backpackers were inclined to feel closer to tradition than on a short trip.

4. Backpackers were more inclined to observe the religious precepts than those on a short trip.

\section{Findings}

In order to examine the research hypotheses, a mean was calculated for the variable of "affiliation with the faith" before analyzing the data. Items Q10, Q13, Q19, Q24 on the variable of "affiliation with the faith" are reverse items and they were encoded accordingly prior to data analysis. Moreover, four items (Q10, Q19, Q24, Q21) were found to have lower reliability than the other items on this variable and were omitted from the analysis. ${ }^{1}$

In the first stage we divided the categorical variable "length of trip" into a dichotomous variable. Participants who reported a trip duration of 0-4 months were defined as the short trip group. Participants who reported a trip duration of 4 months or longer were defined as the long trip group. Table 1 presents descriptive statistics of the sample.

\footnotetext{
${ }^{1}$ Before analysis of the data, a mean was calculated for other variables that were not analyzed, including: proximity of one's close environment to the faith; objection of one's close environment to religious faith; proximity of one's family to the faith; negative thoughts; disappointment with one's environment.
} 
Table 1. Characteristics of the sample - descriptive statistics

\begin{tabular}{|c|c|c|c|c|c|c|c|c|c|}
\hline \multirow{2}{*}{\multicolumn{2}{|c|}{ Variable }} & \multicolumn{4}{|c|}{ Short-trip group } & \multicolumn{4}{|c|}{ Long-trip group } \\
\hline & & $\mathbf{N}$ & Mean & SD & $\%$ & $\mathbf{N}$ & Mean & SD & $\%$ \\
\hline \multicolumn{2}{|c|}{ Experience of feeling close to the faith } & 67 & 2.13 & 1.26 & - & 48 & 2.81 & 1.21 & - \\
\hline \multicolumn{2}{|c|}{ Talking with friends about feeling close to the faith } & 71 & 2.00 & 1.19 & - & 48 & 2.81 & 1.00 & - \\
\hline \multicolumn{2}{|l|}{ Affiliation with the faith } & 71 & 2.79 & 0.49 & & 48 & 2.79 & 0.50 & \\
\hline \multicolumn{2}{|l|}{ Religious observance } & 69 & 2.47 & 0.96 & & 48 & 2.93 & 1.03 & \\
\hline \multicolumn{2}{|c|}{ Disappointment with one's environment } & 69 & 1.98 & 0.82 & & 48 & 2.01 & 0.79 & \\
\hline \multicolumn{2}{|c|}{ Negative thoughts } & 69 & 2.00 & 0.84 & & 48 & 2.29 & 0.26 & \\
\hline \multicolumn{2}{|l|}{ Religiosity in the family } & 69 & 2.81 & 1.16 & & 45 & 2.67 & 1.17 & \\
\hline \multicolumn{2}{|c|}{ Proximity to faith of close environment } & 71 & 4.0 & 0.95 & & 45 & 3.85 & 0.79 & \\
\hline \multicolumn{2}{|c|}{ Objection to faith by close environment } & 69 & 2.53 & 1.00 & & 45 & 2.04 & 0.95 & \\
\hline Gender & $\begin{array}{l}\text { Male } \\
\text { Female }\end{array}$ & 71 & - & - & $\begin{array}{l}18.3 \% \\
81.7 \%\end{array}$ & 45 & - & - & $\begin{array}{l}28.9 \% \\
71.1 \%\end{array}$ \\
\hline Age & $\begin{array}{l}23-20 \\
27-24\end{array}$ & 71 & & & $\begin{array}{l}33.8 \% \\
66.2 \%\end{array}$ & 48 & & & $\begin{array}{l}56.3 \% \\
43.8 \%\end{array}$ \\
\hline Schooling & $\begin{array}{l}\text { Secondary } \\
\text { Student } \\
\text { Academic }\end{array}$ & 71 & - & - & $\begin{array}{l}23.9 \% \\
43.7 \% \\
32.4 \%\end{array}$ & 48 & - & - & $\begin{array}{l}39.6 \% \\
45.8 \% \\
14.6 \%\end{array}$ \\
\hline Life course following the trip & $\begin{array}{l}\text { Acquired new customs } \\
\text { No change }\end{array}$ & 71 & - & - & $\begin{array}{l}5.6 \% \\
94.4 \%\end{array}$ & 48 & - & - & $\begin{array}{l}35.4 \% \\
64.6 \%\end{array}$ \\
\hline Feelings towards tradition & $\begin{array}{l}\text { Grew closer } \\
\text { More distant } \\
\text { No change }\end{array}$ & 71 & & & $\begin{array}{l}19.7 \% \\
80.3 \% \\
-\end{array}$ & 48 & & & $\begin{array}{l}25.0 \% \\
10.4 \% \\
64.6 \%\end{array}$ \\
\hline Religiosity & $\begin{array}{l}\text { Secular } \\
\text { Traditional } \\
\text { Orthodox } \\
\text { Other }\end{array}$ & 71 & & & $\begin{array}{l}68.1 \% \\
29.0 \% \\
2.9 \%\end{array}$ & 48 & & & $\begin{array}{l}50.0 \% \\
33.3 \% \\
12.5 \% \\
4.2 \%\end{array}$ \\
\hline
\end{tabular}

In the first stage, differences were found between long trip participants and short trip participants, with regard to their affiliation with the Jewish faith. The findings show that, in contrast to the research hypothesis, participants on a long trip are not characterized by higher levels of affiliation with the faith than participants on a short trip. These results disconfirm the first research hypothesis, making it unnecessary to continue exploring this hypothesis. Thus, the null hypothesis was not refuted and the first research hypothesis was not confirmed.

In the second stage, differences were found between participants on a long trip and participants on a short trip with regard to conversations with friends on faith-related topics during the trip. The findings show that, compatible with the second research hypothesis, participants on a long trip are more inclined to become engaged in conversations with friends during the trip on faith-related topics than participants on a short trip. Since the research results are in the direction of the hypothesis, we shall further examine the research hypothesis using a t-test for independent samples.

Table 2 presents the results of a t-test for independent samples examining differences between participants on a long trip and participants on a short trip, with regard to conversations with friends during the trip on faith-related topics.

Table 2. T-test examining differences between long-trip and short-trip backpackers with regard to talking with friends about topics related to the faith during the trip

\begin{tabular}{llll}
\hline & Sample size $(\mathbf{n})$ & Mean $(\mathbf{m})$ & Standard deviation (SD) \\
\hline Long-trip group & 48 & $2.81^{* * *}$ & 1.00 \\
Short-trip group & 71 & $2.00^{* * *}$ & 1.19 \\
\hline
\end{tabular}

$* \mathrm{p}<0.05 ; * * \mathrm{p}<0.01 ; * * * \mathrm{p}<0.001$

Table 2 shows that, compatible with the second research hypothesis, participants on a long trip are more inclined to have conversations with their friends during the trip on religious topics than participants on a short trip (one-tailed test, $\mathrm{t}(117)=3.87, \mathrm{SE}=0.21, \mathrm{p}<0.001)$. Hence, the null hypothesis was refuted, determining that participants on a long trip are inclined to have more conversations on religious subjects with friends during the trip than participants on a short trip.

In the third stage, differences were found between participants on a long trip and participants on a short trip with regard to the experience of feeling close to the faith during the trip. The findings show that, compatible with the third research hypothesis, participants on a long trip were more inclined to feel close to the faith during the trip than participants on a short trip. Since the research results are in the direction of the hypothesis, we shall further examine the research hypothesis using a t-test for independent samples.

Table 3 presents the results of a t-test for independent samples examining differences between participants on a long trip and participants on a short trip, with regard to the experience of feeling close to the faith during the trip. 
Table 3. T-test examining differences between participants on a long trip and on a short trip with regard to feeling close to the faith throughout the trip

\begin{tabular}{llll}
\hline & Sample size $(\mathbf{n})$ & Mean $(\mathbf{m})$ & Standard deviation (SD) \\
Long-trip group & 48 & $2.81^{* *}$ & 1.26 \\
Short-trip group & 67 & $2.13^{* *}$ & 1.21 \\
\hline
\end{tabular}

$* \mathrm{p}<0.05 ; * * \mathrm{p}<0.01 ; * * * \mathrm{p}<0.001$

Table 3 shows that, compatible with the third research hypothesis, participants on a long trip were more inclined to feel close to the faith than participants on a short trip (one-tailed test, $\mathrm{t}(113)=2.88, \mathrm{SE}=0.2301, \mathrm{p}<0$ ). If so, the null hypothesis was refuted, determining that participants on a long trip are inclined to feel closer to the faith during the trip than participants on a short trip.

In the fourth stage, differences were found between participants on a long trip and participants on a short trip with regard to observing religious precepts after the trip. The findings show that, according to the fourth research hypothesis, participants on a long trip are more inclined to observe religious precepts than participants on a short trip. Since the research results are in the direction of the hypothesis, we shall further examine the research hypothesis using a t-test for independent samples.

Table 4 presents the results of a t-test for independent samples examining differences between participants on a long trip and participants on a short trip, with regard to their level of religious observance.

Table 4. T-test examining differences between participants on a long trip and on a short trip with regard to their level of religious observance

\begin{tabular}{|c|c|c|c|}
\hline & Sample size (n) & Mean (m) & Standard deviation (SD) \\
\hline Long-trip group & 48 & $2.93 * *$ & 0.96 \\
\hline Short-trip group & 69 & $2.47 * *$ & 1.03 \\
\hline
\end{tabular}

Table 4 shows that, compatible with the fourth research hypothesis, participants on a long trip are more inclined to observe religious precepts than participants on a short trip (one-tailed test, $t(115)=2.45, \mathrm{SE}=0.1801, \mathrm{p}<0$ ). Hence, the null hypothesis was refuted, determining that participants on a long trip are more inclined to observe religious precepts than participants on a short trip.

\section{Conclusion}

The backpacking trip undertaken by young Israelis after completing their army service has become a wide and well-known social phenomenon and an important part of the life of twenty year olds. Israeli backpackers take with them to the trip a significant part of Israeli culture and of the Jewish faith. In the enclaves created by Israelis the Hebrew language is often heard. Chabad Houses spread throughout the Far East serve Israelis as a place to gather, enabling them to maintain their religious life, customs, and traditions. Israelis visit Chabad Houses on festival eves and Friday nights, participate in courses on Kabbalah, and hear lessons by the Chabad emissary.

The purpose of the current study was to explore the affiliation of Israeli backpackers with the Jewish faith while on the big trip. We examined whether participants on a long trip (four or more months) show a greater level of affiliation with the faith than those on a short trip (up to four months). We examined whether participants on a long trip were more inclined to hold conversations with their trip mates about feeling close to the faith than participants on a short trip, and whether participants on a long trip were more inclined to feel close to the Jewish tradition (during the trip) than participants on a long trip. We also explored whether participants on a long trip are more inclined to observe the religious precepts than participants on a short trip.

We hypothesized that the physical distance from Israel would induce affiliation and a need to become closer to Jewish tradition. We hypothesized that the longer the trip the higher the level of affiliation with the faith. This hypothesis was refuted. Another hypothesis was that backpackers on a long trip would be more inclined to talk about feeling close to the faith than those on a short trip. This hypothesis was confirmed. Furthermore, we hypothesized that backpackers on a long trip would tend to feel closer to the tradition than backpackers on a short trip. This hypothesis too was confirmed. We also hypothesized that backpackers on a long trip would be more inclined to observe religious precepts than backpackers on a short trip. This hypothesis was confirmed.

After presenting the research hypotheses and the results of findings from the questionnaires, we can conclude that the backpacking trip is a source of attraction to and affiliation with the Jewish faith and tradition. The longer the backpacking trip the greater the affiliation with tradition, both during and after the trip. Israeli backpackers have a need to be close to other Israeli travelers, to the experience of Jewish tradition, Chabad houses, Friday night dinners, and the traditional Jewish ambience, connecting them to Israel and to their Jewish faith. We recommend further research 
investigating the effect of the backpacking trip on religious backpackers, their exposure and the time spent with secular backpackers, on their religious observance during the trip, and whether there is an effect on how close they feel to the faith.

\section{Acknowledgements}

The authors wish to thank Ofir Vais Peled and Einav Levite, undergraduate students in the social sciences at Ariel University, for their assistance in collecting data for this study.

\section{References}

Almog, O. (2004). Farewell to Srulik. Haifa: Haifa University and Zmora Bitan. [in Hebrew]

Azulay, N., \& Tabory, E. (2008). From a house of study to a house of prayer: Cultural and religious developments in Israel's nonreligious expanse. [in Hebrew]

Bar, A. (2000). A continent in a backpack. http://www.peopleil.org/details.aspx?itemID=30267\&searchMode=0\&index=1_[in Hebrew]

Ben-Rafael, E., \& Ben-Chaim, L. (2006). Jewish identities in an era of multiple modernities. [in Hebrew]

Boni-Noah, H. (2012). The secular pilgrim. Bitchon Pnim, 2, 32-33. [in Hebrew]

Calderon, N. (2000). Multiculturalism versus pluralism in Israel. Haifa: Zmora Bitan. [in Hebrew]

Dayan, A. (2004, April 7). The bad energies of the backpacker. Ha'aretz. [in Hebrew]

Finkel, O. (2003, July 11). Climbing in Bolivia. www/lobo.co.il. [in Hebrew]

Ghinsberg, Y. (1985). Back from Tuichi. Tel Aviv. [in Hebrew]

HaElyon, Y. (1980, September 10). The Israeli Muchileros. Ma'ariv. [in Hebrew]

Halfon, E. (1991, June 14). Thailand is ours, bro. Ha'ir. [in Hebrew]

Hass, H. (1992). Part II - Time, Chapter 2 - Friday, Saturday, and holidays. In E. Katz, H. Hass, S. Weitz, H. Adoni, M. Gurevitch, \& M. Schiff (eds.), Leisure culture in Israel - Changes in types of cultural activity 1970-1990 (pp. 65-87). Guttman Institute for Practical Social Research. [in Hebrew]

Huizinga, J. (1966). Homo Ludens. Jerusalem: Hebrew University. [in Hebrew]

Katz, E., \& Yanovitsky, Y. (1999). Communications and leisure culture in Israel. Open University. [in Hebrew]

Lee, V. (2003, November 6). In Seattle I established the uprising of the Jews. Ha'aretz Supplement. [in Hebrew]

Maoz, D. (2002). India will love me. Jerusalem. [in Hebrew]

Maoz, D. (2003). Backpackers - Study of the new nomads. Masa Acher, 136. [in Hebrew]

Maoz, D. (2006). Every age and its backpack. In N. Elhanan (ed.), From India till here - Israeli thinkers write about India and their Judaism. Jerusalem: Reuven Mass. [in Hebrew]

Noy, C. (2003). Narratives of hegemonic masculinity: Presentations of body and space in Israeli backpackers' narrative. Israeli Sociology, 75-120.

Paltin, E. (2003). The craziness of the trip or a trip to craziness? Tel Aviv. [in Hebrew]

Sagiv, N. (2001). Look for me in the far reaches of the earth. Netanya. [in Hebrew]

Samocha, S. (2003, October 5). One in fifty will return from India the worse for wear. Ha'aretz. [in Hebrew]

Saposnik, A. (2009). A secularized Zionist sacred and the making of the new Jew. [in Hebrew]

Shafran, N. (1999). Reflection of the Petra journey affair in Hebrew literature. Iyunim Bitkumat Yisrael, 9, 490-525. [In Hebrew]

Shafran, N. (2003, April). Development of the Israeli backpacking phenomenon. Hado'ar. [in Hebrew]

Shafran, N. (2006). From the hikes of the Palmach to the muchileros. Panim, 35, 48-83. [in Hebrew]

Taub, G. (2003, September 28). The New Israelis. Ha'aretz Supplement. https://www.itu.org.il/?CategoryID=957\&ArticleID=6703 [in Hebrew]

Turner, V. (1977). Process, system, and symbol: A new anthropological synthesis. Discoveries and Interpretations: Studies in Contemporary Scholarship, 106(3), 61-80.

Uriely, N., Yonay, Y., \& Simchai, D. (2002). Backpacking experiences. A type and form analysis. Annals of Tourism Research, 29(2), 520-538.

\section{$(\mathrm{Cc}) \mathrm{BY}$}

This work is licensed under a Creative Commons Attribution 3.0 License. 